\title{
Rearrangement of leaf traits with changing source-sink relationship in blueberry (Vaccinium corymbosum $\mathrm{L}$.) leaves
}

\author{
E. JORQUERA-FONTENA* ${ }^{*}$ M. ALBERDI ${ }^{* * * * *}$, M. REYES-DÍAZ ${ }^{* * * * *}$, and N. FRANCK ${ }^{\#,+}$ \\ Programa de Doctorado y Magister en Ciencias de Recursos Naturales, Universidad de La Frontera, Casilla 54-D, \\ Temuco, Chile* \\ Departamento de Ciencias Químicas, Universidad de La Frontera, Casilla 54-D, Temuco, Chile** \\ Center of Plant-Soil Interaction and Natural Resources, Biotechnology, Scientific, and Technological Bioresource \\ Nucleus (BIOREN), Universidad de La Frontera, Casilla 54-D, Temuco, Chile ${ }^{* * *}$ \\ Centro de Estudios de Zonas Áridas, Facultad de Ciencias Agronómicas, Universidad de Chile, Casilla 129, \\ Coquimbo, Chile
}

\begin{abstract}
The source-sink relationship is one of major determinants of plant performance. The influence of reproductive sink demand on light-saturated photosynthesis $\left(P_{\max }\right)$, dark respiration $\left(R_{\mathrm{D}}\right)$, stomatal conductance $\left(g_{\mathrm{s}}\right)$, intrinsic water-use efficiency $\left(\mathrm{WUE}_{\mathrm{i}}\right)$, contents of soluble sugar (SSC), nitrogen, carbon, and photosynthetic pigments was examined in blueberry (Vaccinium corymbosum L. cv. 'Brigitta') during the final stage of rapid fruit growth. Measurements were performed three times per day on developed, sun-exposed leaves of girdled shoots with $0.1,1$, and 10 fruit per leaf $(0.1 \mathrm{~F}: \mathrm{L}, 1 \mathrm{~F}: \mathrm{L}$, and 10F:L, respectively) and nongirdled shoots bearing one fruit per leaf (NG). Girdling and lower fruit amount induced lower $P_{\max }, g_{\mathrm{s}}, \mathrm{N}$, and total chlorophyll (Chl) and higher $\mathrm{WUE}_{\mathrm{i}}, \mathrm{SSC}, R_{\mathrm{D}}, \mathrm{Chl} a / b$ ratio and carotenoids-to-chlorophylls ratio (Car/Chl) for the $1 \mathrm{~F}: \mathrm{L}$ and $0.1 \mathrm{~F}: \mathrm{L}$ treatments. The impact of girdling was counterbalanced by $10 \mathrm{~F}: \mathrm{L}$, with $\mathrm{NG}$ and $10 \mathrm{~F}: \mathrm{L}$ having similar values. Variables other than $P_{\max }, R_{\mathrm{D}}, g_{\mathrm{s}}, \mathrm{WUE}_{\mathrm{i}}$, and SSC were unaffected throughout the course of the day. $P_{\max }$ and $g_{\mathrm{s}}$ decreased during the course of the day, but $g_{\mathrm{s}}$ decreased more than $P_{\max }$ in the afternoon, while WUE $\mathrm{i}_{\mathrm{i}}$ was increasing in almost all treatments. SSC increased from the morning until afternoon, whereas $R_{\mathrm{D}}$ peaked at noon regardless of the treatment. Generally, $P_{\max }$ was closely and negatively correlated to SSC, indicating that sugar-sensing mechanisms played an important role in regulation of blueberry leaf photosynthesis. With respect to treatments, $P_{\max }$ and N content were positively related, while $R_{\mathrm{D}}$ was not associated to substrate availability. The enhanced Car/Chl ratio showed a higher photoprotection under the lower sink demand. Changes in the source-sink relationship in 'Brigitta' blueberry led to a rearrangement of physiological and structural leaf traits which allowed adjusting the daily balance between carbon assimilation and absorbed light energy.
\end{abstract}

Additional key words: gas exchange; nitrogen; photosynthetic pigments; soluble sugars.

\section{Introduction}

The source-sink balance is one of the major determinants of plant growth and metabolism, and its understanding can be useful for predicting effects of agronomical practices affecting either fruit or leaf (or both) and for their inclusion in simulation models. In fruit crops, it is generally assumed that a sink limitation during periods of low carbohydrate demands by fruits (due to either low fruit load or periods of low or absent fruit growth), lead to a downregulation of photosynthetic activity of source leaves. This has been proposed to be caused by an accumulation of nonstructural carbohydrates in leaves as a result of disequilibrium between carbon assimilation and assimilate

Received 25 August 2015, accepted 26 January 2016, published as online-first 20 February 2016.

${ }^{+}$Corresponding author; phone: +5699298 0887, email: nfranck@uchile.cl

Abbreviations: AM - measurements at 08:00-10:40; Car - carotenoids; Chl - chlorophyll; Chl tot - total chlorophylls; DM - dry mass; FM - fresh mass; $g_{\mathrm{s}}$ - stomatal conductance to water vapour; NG - nongirdled shoots; $P_{\max }$ - light-saturated photosynthesis; PM measurements at 17:00-19:40; $R_{\mathrm{D}}$ - dark respiration rate; SSC - soluble sugar concentration; WUE $\mathrm{i}_{\mathrm{i}}$ - intrinsic water-use efficiency. Acknowledgements: The first author thanks to 'Agrícola Berries San Luis' for facilitating the use and maintenance of the experimental plot. Aureliano Troncoso, Francisco Alfaro, and Jessica Yañez for their valuable help in the collection of data and Dr. Francisco Matus for his pertinent suggestions. E. Jorquera-Fontena was funded by CONICYT (Chile) through Ph.D. scholarship and FONDEF D06I1 100, and by Universidad de La Frontera (Temuco, Chile) through Project FRO0601. N. Franck acknowledges FONDECYT grant 1130509. 
consumption and translocation (Hendrix and Huber 1986), which decreases the expression of photosynthetic gene promoters (Koch et al. 1992, Jang and Sheen 1994, Eberhard et al. 2008). However, downregulated photosynthesis was disengaged to an excess of nonstructural carbohydrates (particularly sugars) in Citrus (Nebauer et al. 2011) and Nicotiana tabacum L. under high $\mathrm{CO}_{2}$ concentration (Ludewig and Sonnewald 2000).

The reduction in carbon use and assimilation may lead to structural leaf rearrangements if the plant is not able to develop new sink capacity at a medium time scale (days or weeks). In Mangifera indica L., leaf nitrogen concentration in shoots subjected to high fruit load between 80-90 d after being in bloom, was higher than in those subjected to low fruit load (Urban et al. 2004), suggesting that proteins of the Calvin cycle and thylakoids were adjusted to a given reproductive sink demand. On the other hand, Chl concentration has been found to be higher in leaves of fruiting Malus $\times$ domestica Borkh trees than that in fruitless trees from about $30 \mathrm{~d}$ before harvest (Wünsche et al. 2005). Chl concentration was also higher in fruiting shoots of Olea europaea L. than that in fruitless shoots, which was accompanied by higher leaf mass-to-area ratio (Proeitii 2000). These rearrangements can contribute to restoration of the balance between carbon assimilation and absorbed light energy and can be viewed as a 'sort' of acclimation to changing source-sink relationships, which prevents premature cell death and enables efficient nutrient partitioning (Wingler et al. 2004).

Many studies on fruit crop physiology have been based on a source-sink approach, among them, there are studies dealing with photoinhibition (Duan et al. 2008), fruit

\section{Materials and methods}

Experimental site and plant material: The experiment was carried out during the 2010-2011 season on a commercial orchard of blueberries (Vaccinium corymbosum L.) cv. Brigitta (deciduous, mid-season cultivar harvested from midlle of January), located in La Araucanía Region, Chile (38 $\left.29^{\prime} \mathrm{S}, 72^{\circ} 23^{\prime} \mathrm{W}\right)$. Four-year-old plants planted in an andisol soil at $0.9 \mathrm{~m}$ on north-south oriented rows, which were $3 \mathrm{~m}$ apart from each other, were used. Irrigation was applied as needed (between November and March) at a rate of 10 to $20 \mathrm{~mm}$ per week. Fertilizers were supplied during the growing season at a rate of $70 \mathrm{~kg}(\mathrm{~N})$ $\mathrm{ha}^{-1}, 40 \mathrm{~kg}\left(\mathrm{P}_{2} \mathrm{O}_{5}\right) \mathrm{ha}^{-1}$, and $75 \mathrm{~kg}\left(\mathrm{~K}_{2} \mathrm{O}\right) \mathrm{ha}^{-1}$. Insects and diseases were controlled following commercial standards. The experimental site presents a temperate climate, where rainfall is distributed throughout the year $(1,200 \mathrm{~mm}$ per year), with the highest precipitation during the winter and a moderate dry season of less than four months in the summer.

Sink-source manipulation: During the second fruit growth stage (70 d after full bloom), 72 sun-exposed fruitbearing shoots from 36 homogenous plants (two shoots per quality (e.g., Famiani et al. 1997), and regulation of photosynthesis (e.g., Layne and Flore 1995, Iglesias et al. 2002, Nebauer et al. 2011). In the case of blueberry (Vaccinium corymbosum L.), studies on source-sink balance have mainly focused on vegetative and reproductive responses of plants (e.g., Swain and Darnell 2002, Strik et al. 2003) and recently on some fruit quality traits (Jorquera-Fontena et al. 2014); however, Maust et al. (1999) reported that a low fruit load induces a reduction of net leaf photosynthesis in a southern blueberry cultivar (hybrids of $V$. corymbosum L. with other Vaccinium species), although they did not evaluate if non-structural carbohydrates mediated this depressed carbon assimilation response. Up to now, little is known about the effect of reproductive sink demand on physiological leaf traits, such as light-saturated photosynthesis $\left(P_{\max }\right)$, stomatal conductance to water vapour $\left(g_{\mathrm{s}}\right)$, dark respiration $\left(R_{\mathrm{D}}\right)$, and intrinsic water-use efficiency $\left(\mathrm{WUE}_{\mathrm{i}}=P_{\max } / g_{\mathrm{s}}\right)$; as well as leaf traits, such as nitrogen, carbon, and pigment concentrations.

Considering that blueberry leaves exhibit different carbon assimilation responses to a changing reproductive sink demand, the aim of this study was to evaluate the impact of the source-sink relationship by assessing the effects of fruit load and girdling on physiological and structural leaf traits, elucidating if leaf soluble sugar concentration mediates a depressed photosynthesis response to low reproductive sink demand. In order to reach this aim, fully developed sun exposed blueberry leaves were subjected to different reproductive sink demands and evaluated during the course of the day.

plant) were selected for uniformity in vigour and fruit load (1-1.4 fruits per leaf) and randomly assigned to apply four treatments on 18 replicated shoots. The fruit load selected was the typical condition found in plants. Treatments were applied by removing fruits or leaves and consisted in: nongirdled shoots with one fruit per leaf $(\mathrm{NG})$ and girdled shoots with $10(10 \mathrm{~F}: \mathrm{L})$, one $(1 \mathrm{~F}: \mathrm{L})$ or $0.1(0.1 \mathrm{~F}: \mathrm{L})$ fruit per leaf. Girdling was applied by removing a 1-cm-wide band of bark at the shoot base. The exposed tissues were protected with pruning seal to avoid drying and fungal infection. To restrict sink demands for assimilates mainly to fruits, immature leaves and the apical and axillary buds were removed after applying the treatments. The rest of the plant remained intact; no fruit drop was observed during the course of the trial. The NG treatment was used as a reference for assessing the effects of girdling (as compared to $1 \mathrm{~F}: \mathrm{L}$, in which the fruit load was equivalent to the $\mathrm{NG}$ treatment).

Gas-exchange measurements: During the final stage of rapid fruit growth, the $P_{\mathrm{max}}, R_{\mathrm{D}}$, and $g_{\mathrm{s}}$ were measured three times per day [08:00-10:40 h (AM), 13:00-15:40 h (noon), 
and 17:00-19:40 h (PM)], on three cloudless days, 10, 15, and $20 \mathrm{~d}$ after initiating the treatments (i.e., 80, 85 and $90 \mathrm{~d}$ after full bloom). Six fruiting shoots per treatment were randomly selected to be used on each day of the measurement. Thus, two replicated shoots per time of the day were used. In these shoots, three fully developed sunexposed leaves (mean area of $15.74 \pm 0.53 \mathrm{~cm}^{-2}$ ) close to developing fruits, were measured and then harvested. Samples were immediately placed in a cooler and taken to a freezer in the proximity of the experimental plot. Thereafter, samples were carried to the laboratory for chemical analysis (see below). An infrared gas analyser (Li-6400, LICOR, Nebraska, USA) connected to a broadleaf chamber $(2 \times 3 \mathrm{~cm})$ and with automatic control of leaf temperature, PPFD, and $\mathrm{CO}_{2}$ concentration, was used for the measurements. We assessed $P_{\max }$ applying a saturating PPFD dose of 1,500 $\mu \mathrm{mol}$ (photon) $\mathrm{m}^{-2} \mathrm{~s}^{-1}$ (based on preliminary evaluations of photosynthesis lightresponse curves; data not shown). The $g_{\mathrm{s}}$ was recorded for this condition. In the same leaf of the above mentioned evaluation, $R_{\mathrm{D}}$ at a PPFD of $0 \mu \mathrm{mol}$ (photon) $\mathrm{m}^{-2} \mathrm{~s}^{-1}$ was recorded when it reached stable value $(\approx 5 \mathrm{~min})$. For all sampled leaves, the $\mathrm{WUE}_{\mathrm{i}}$ was calculated as $P_{\max } / g_{\mathrm{s}}$. Leaf temperature was set at $20^{\circ} \mathrm{C}$ and ambient $\mathrm{CO}_{2}$ and $\mathrm{H}_{2} \mathrm{O}$ vapour concentrations were used during measurements. Weather conditions were similar on each measurement day with a mean day time (from dawn to dusk) PPFD of $1,061 \pm 76 \mu$ mol(photon) $\mathrm{m}^{-2} \mathrm{~s}^{-1}$ [with a midday maximum of 2,139.5 $\mu \mathrm{mol}$ (photon) $\mathrm{m}^{-2} \mathrm{~s}^{-1}$ at about 13:30-14:30 h], air temperature of $19.98 \pm 2.30^{\circ} \mathrm{C}$, relative humidity of $59.3 \pm 8.92 \%$, and water vapour pressure deficit of $1.03 \pm$ $0.12 \mathrm{kPa}$. Rainfall was absent during days of measurements. The weather conditions were similar in the days before evaluations.

Chemical analysis: Leaf soluble sugar concentration (SSC) was extracted from frozen tissue in $86 \% \mathrm{v} / \mathrm{v}$ ethanol with agitation for $24 \mathrm{~h}$ and then centrifuged at 13,000 $\times g$ for $10 \mathrm{~min}$. The supernatant was depigmented with chloroform in a 1:3 (v/v) mixture (extract:chloroform).

\section{Results}

Gas exchange and soluble sugar concentration: The treatments significantly affected the daily mean $P_{\max }$ of blueberry cv. 'Brigitta' leaves (Fig. $1 A$ ). Decreasing fruit load resulted in a 54\% lower $P_{\max }$ when comparing $0.1 \mathrm{~F}: \mathrm{L}$ to $10 \mathrm{~F}: \mathrm{L}$ treatments, whereas the effect of girdling reduced $P_{\max }$ in average by $35 \%$ when comparing $1 \mathrm{~F}: \mathrm{L}$ with NG. The daily mean $P_{\max }$ was statistically equivalent for the NG and 10F:L treatments. From AM to PM, $P_{\max }$ was reduced between 22 and $50 \%$, depending on the treatment (Fig. $1 A$ ). For the $0.1 \mathrm{~F}: \mathrm{L}$ treatment, $P_{\max }$ stabilized at a low value from noon onwards, contrasting with the other treatments, where $P_{\max }$ was only significantly reduced in the afternoon.
SSC in supernatant was determined spectrophotometrically by the resorcinol method (Roe 1934) at $520 \mathrm{~nm}$, using sucrose as standard (Genesys 5, Spectronic Unicam, USA).

Total $\mathrm{N}$ and $\mathrm{C}$ contents of each sample were measured on dry leaves using EuroEA 3000 elemental analyser (EuroVector, Italy), designed for CHNS analysis of organic compounds. Water content of these samples was recorded as the difference between fresh (FM) and dry mass (DM).

Photosynthetic pigments were extracted in dark from frozen leaf tissue with $96 \%$ cold ethanol and determined by a spectrophotometer (Genesys 5, Spectronic Unicam, USA) (Lichtenthaler and Wellburn 1983). Absorbances of Chl $a$, Chl $b$, and carotenoids (Car) were determined in extracts at wavelengths of 663,645 , and $470 \mathrm{~nm}$, respectively. Concentrations of pigments were calculated by equations of Lichtenthaler and Wellburn (1983).

Data analysis: Data obtained on each date of measurement were pooled to evaluate both the effect of treatment and the combined effect of treatment and period of the day through analysis of variance (ANOVA) followed by multiple comparison of means (Tukey's test at $P<0.05$ ). Data were pooled based on a previous ANOVA, which revealed that date of measurement did not affect the results obtained for each treatment and period of the day. A correlation analysis with a $P$-value adjusted through Holm's method was performed to evaluate the degree of association among variables. All data analyses and methods used for fitting models were carried out with $R$ free software through ' $R$ ' Commander (Rcmdr version 1.8 -3 in $R$ version 2.14.2), and ' $m$ ' and ' $n l s$ ' functions ( $R$ version 2.15.0), respectively. Results from chemical analysis were expressed on a mass basis because the massto-leaf area ratio of the samples was unaffected by treatments $\left[122.45 \pm 17 \mathrm{~g}(\mathrm{DM}) \mathrm{m}^{-2}, n=48\right.$, data not shown], thus the hypothetical changes induced by the treatments can be attributed to a change in concentration of the variable.

Daily mean $g_{\mathrm{s}}$ was significantly affected by the treatments $\left(\right.$ Fig. $1 B$ ). The greatest effect on $g_{\mathrm{s}}$ was brought about by fruit load, with the $10 \mathrm{~F}: \mathrm{L}$ treatment exhibiting $g_{\mathrm{s}}$ values more than three times higher than those observed in $0.1 \mathrm{~F}: \mathrm{L}$. On the other hand, girdling reduced $g_{\mathrm{s}}$ in average by around $50 \%(1 \mathrm{~F}: \mathrm{L} v s$. NG). In general, the response of $g_{\mathrm{s}}$ to the treatments paralleled those of $P_{\max }$ over the day (Fig. $1 B$ ). The $g_{\mathrm{s}}$ values decreased in the range of 11 to $66 \%$ from AM to PM, with the 10F:L treatment showing the largest variation and $1 \mathrm{~F}: \mathrm{L}$ the smallest one. For the whole data set, $P_{\max }$ and $g_{\mathrm{s}}$ were closely and positively related, with $P_{\max }$ accounting for $78 \%$ of the variance of $g_{\mathrm{s}}$ (Fig. 2). 


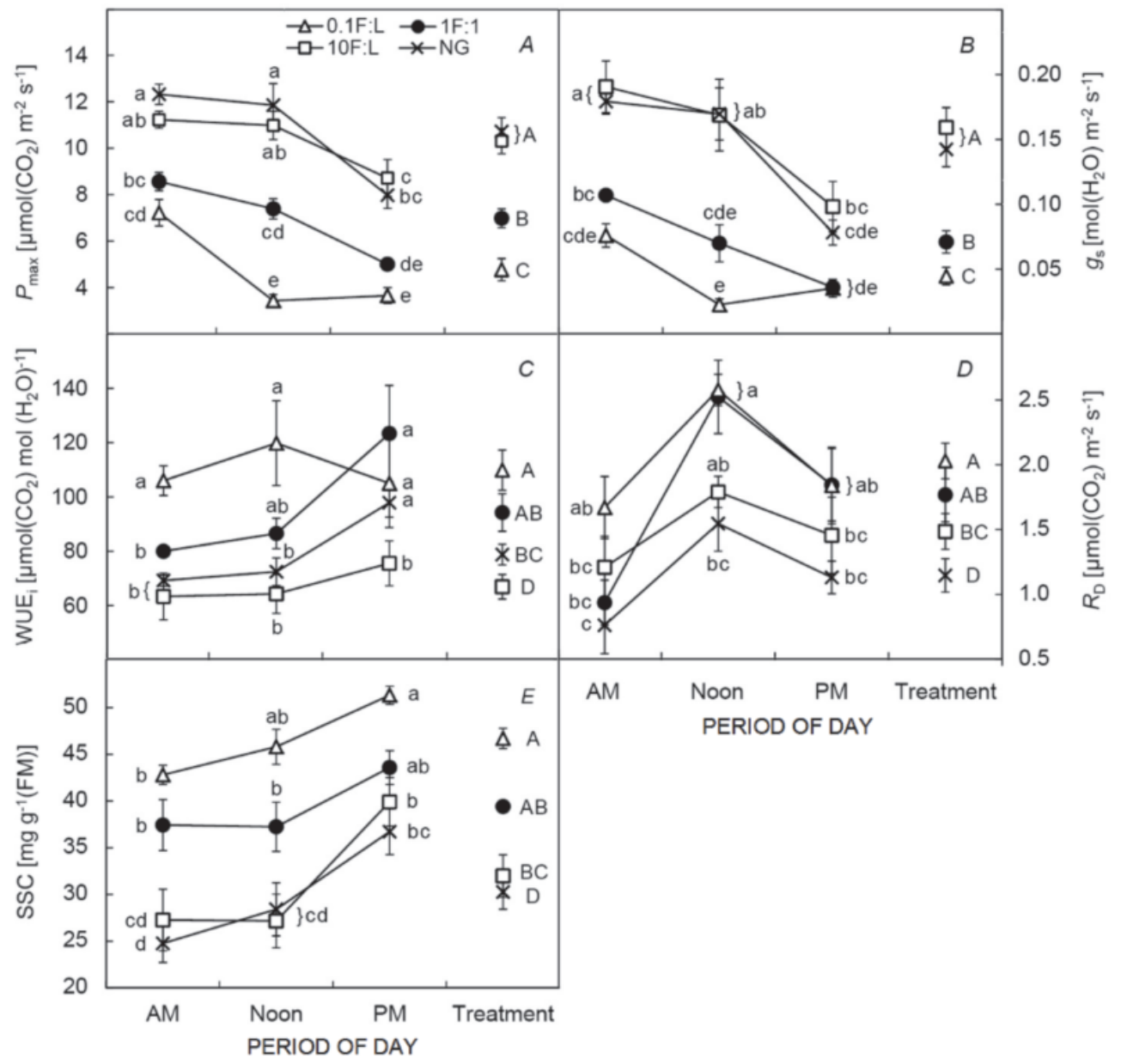

Fig. 1. Light-saturated photosynthesis $\left(P_{\max }\right)(A)$, stomatal conductance to water vapour $\left(g_{\mathrm{s}}\right)(B)$, intrinsic water-use efficiency $\left(\mathrm{WUE}_{\mathrm{i}}\right)(C)$, dark respiration $\left(R_{\mathrm{D}}\right)(D)$, and soluble sugar concentration $(\mathrm{SSC})(E)$ of 'Brigitta' blueberry leaves from girdled shoots bearing $10(10 \mathrm{~F}: \mathrm{L}), 1(1 \mathrm{~F}: \mathrm{L})$, and $0.1(0.1 \mathrm{~F}: \mathrm{L})$ fruits per leaf and nongirdled shoots with one fruit per leaf $(\mathrm{NG})$. Mean of treatments $(n=18)$ and period of the day $(n=6)$, standard errors and letters indicating significantly different values at $P<0.05$ (Tukey's test) both for daily mean of treatments (uppercase letters) and the combined effect of treatment and period of the day (lowercase letters) are presented. FM - fresh mass.

The mean intrinsic water-use efficiency $\left(\mathrm{WUE}_{\mathrm{i}}\right)$, which is the ratio between $P_{\max }$ and $g_{\mathrm{s}}$, was affected by treatments (Fig. 1C), such that values increased by $83 \%$ from $10 \mathrm{~F}: \mathrm{L}$ to $0.1 \mathrm{~F}: \mathrm{L}$ and by $32 \%$ from NG to $1 \mathrm{~F}: \mathrm{L}$. The course of the day induced increases in $\mathrm{WUE}_{\mathrm{i}}$ values for the $10 \mathrm{~F}: \mathrm{L}, 1 \mathrm{~F}: \mathrm{L}$, and $\mathrm{NG}$ treatments, reaching values significantly different only in the NG treatment.

Daily mean $R_{\mathrm{D}}$ increased with decreasing fruit load and with girdling (Fig. 1D). The highest $R_{\mathrm{D}}$ values were observed in the $0.1 \mathrm{~F}: \mathrm{L}$ treatment, which were $77 \%$ higher than those of the NG treatment exhibiting the lowest $R_{\mathrm{D}}$ values. While girdling increased $R_{\mathrm{D}}$ by $54 \%$, the lowest fruit load increased $R_{\mathrm{D}}$ by $37 \%$. Regarding the period of the day, $R_{\mathrm{D}}$ followed a similar pattern in all treatments, rising between 48 and $128 \%$ from the morning to noon and decreasing in the afternoon to values similar to those observed in the morning (Fig. 1D).

Daily mean foliar SSC was significantly affected by the treatments (Fig. 1E). The SSC was $30 \%$ higher in the $0.1 \mathrm{~F}: \mathrm{L}$ than in the $10 \mathrm{~F}: \mathrm{L}$ treatment. Girdling resulted in a $23 \%$ increase in SSC (1F:L vs. NG), whereas girdled shoots with the highest fruit load (10F:L) exhibited statistically similar values to NG. Diurnal variations of SSC increased as that sink demand grew (Fig. $1 E$ ); thus, from AM to PM, SSC of the NG and 10F:L treatments increased by around $47 \%$, whereas SSC of the $1 \mathrm{~F}: \mathrm{L}$ and $0.1 \mathrm{~F}: \mathrm{L}$ treatments increased by 8 and 19\%, respectively.

For the whole data set, variations of $P_{\max }$ could be largely explained as a negative function of SSC. Thus, SSC accounted for about $78 \%$ of the variance in $P_{\max }$ (Fig. 3). 


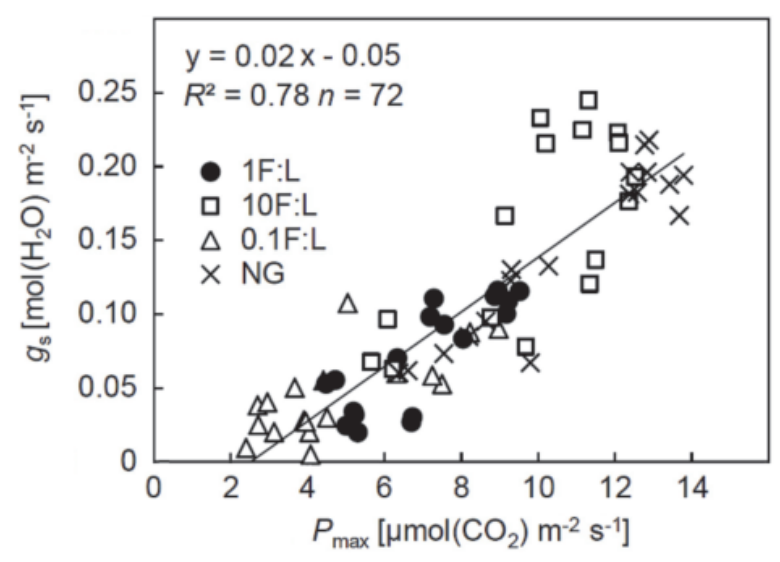

Fig. 2. Relationship between stomatal conductance to water vapour $\left(g_{\mathrm{s}}\right)$ and light-saturated photosynthetic rate $\left(P_{\max }\right)$ of 'Brigitta' blueberry leaves from girdled shoots bearing $10(10 \mathrm{~F}: \mathrm{L}), 1(1 \mathrm{~F}: \mathrm{L})$, and $0.1(0.1 \mathrm{~F}: \mathrm{L})$ fruits per leaf and nongirdled shoots with one fruit per leaf $(\mathrm{NG})$. Nonlinear regression and statistical $R^{2}$ are presented (linear regressions were not significantly different between treatments).

Nitrogen and carbon concentrations: Daily means of $\mathrm{N}$ and the $\mathrm{C} / \mathrm{N}$ ratio were affected by the treatments (Table 1), whereas the course of the day did not induce changes in these variables (data not shown). As illustrated in Table 1, leaf $\mathrm{N}$ steadily diminished with decreasing fruit load, reaching a difference of $17 \%$ between $0.1 \mathrm{~F}: \mathrm{L}$ and 10F:L treatments. On the other hand, the girdling treatment significantly reduced $\mathrm{N}$ by $15 \%$ ( $1 \mathrm{~F}: \mathrm{L} v s$. $\mathrm{NG})$. The daily mean $\mathrm{C}$ remained unchanged by the treatments and the period of the day, thus the $\mathrm{C} / \mathrm{N}$ responded to treatments according to the previously described effect of treatments on $\mathrm{N}$ (Table 1).

Photosynthetic pigments: No significant differences between the treatments were observed for photosynthetic pigments when comparing periods of the day (data not

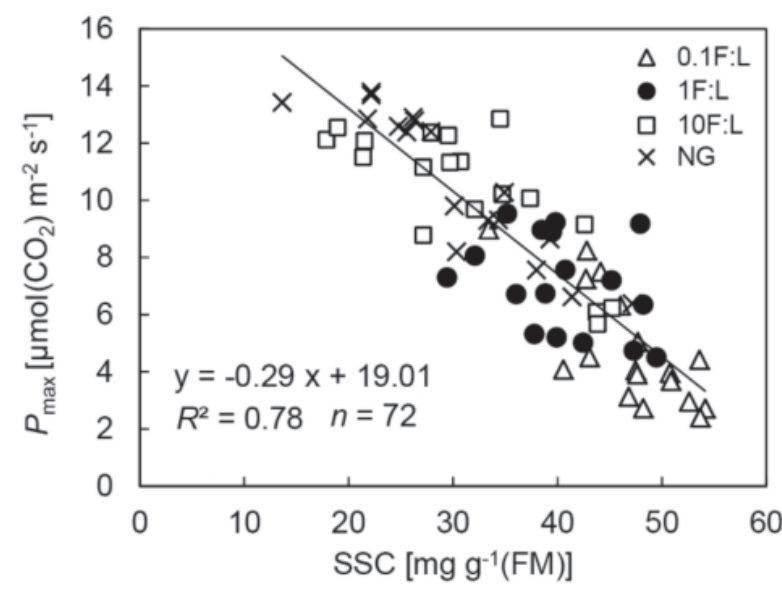

Fig. 3. Relationship between light-saturated photosynthetic rate $\left(P_{\max }\right)$ and soluble sugar concentration (SSC) of 'Brigitta' blueberry leaves from girdled shoots bearing 10 (10F:L), $1(1 \mathrm{~F}: \mathrm{L})$, and $0.1(0.1 \mathrm{~F}: \mathrm{L})$ fruits per leaf and nongirdled shoots with one fruit per leaf $(\mathrm{NG})$. Linear regression and statistical $R^{2}$ are presented. FM - fresh mass.

shown). Photosynthetic pigments as affected by the treatments are shown in Table 2. In girdled shoots, the total chlorophyll $\left(\mathrm{Chl}_{\text {tot }}\right)$ was significantly reduced by fruit load, with the $0.1 \mathrm{~F}: \mathrm{L}$ treatment having $19 \%$ lower $\mathrm{Chl}_{\text {tot }}$ than that of the 10F:L treatment. Girdling, by itself, did not affect $\mathrm{Chl}_{\text {tot }}$ as shown by the absence of significant differences between NG and and girdled shoots. The Chl $a / b$ ratio was significantly lower in the highest sinkdemanding treatment of girdled branches as compared to intermediate and low fruit load treatments. The mean daily Car content was unaffected by the treatments. Daily mean $\mathrm{Car} / \mathrm{Chl}_{\text {tot }}$ ratio was significantly affected by treatments, increasing by $80 \%$ from $10 \mathrm{~F}: \mathrm{L}$ to $0.1 \mathrm{~F}: \mathrm{L}$ and by $30 \%$ due to girdling. In the same line of the other studied variables, the $10 \mathrm{~F}: \mathrm{L}$ and $\mathrm{NG}$ treatments showed equivalent values.

Table 1. Nitrogen $(\mathrm{N})$ and carbon $(\mathrm{C})$ concentration, and $\mathrm{C} / \mathrm{N}$ ratio of 'Brigitta' blueberry leaves from girdled branches with 10 (10F:L), $1(1 \mathrm{~F}: \mathrm{L})$, and $0.1(0.1 \mathrm{~F}: \mathrm{L})$ fruits per leaf and nongirdled branches bearing one fruit per leaf $(\mathrm{NG})$. Means of treatments $(n=18)$, standard errors, effect of treatment and letters indicating significantly different values at $P<0.05$ (Tukey's test) are presented. DM - dry mass.

\begin{tabular}{llll}
\hline Treatment & $\mathrm{N}\left[\mathrm{mg} \mathrm{g}^{-1}(\mathrm{DM})\right]$ & $\mathrm{C}\left[\mathrm{mg} \mathrm{g}^{-1}(\mathrm{DM})\right]$ & $\mathrm{C} / \mathrm{N}$ \\
\hline $\mathrm{NG}$ & $22.37 \pm 0.38^{\mathrm{A}}$ & $465.39 \pm 16.74^{\mathrm{A}}$ & $20.83 \pm 0.82^{\mathrm{A}}$ \\
$10 \mathrm{~F}: \mathrm{L}$ & $21.87 \pm 0.92^{\mathrm{A}}$ & $451.88 \pm 7.32^{\mathrm{A}}$ & $20.88 \pm 1.10^{\mathrm{A}}$ \\
$1 \mathrm{~F}: \mathrm{L}$ & $18.97 \pm 0.75^{\mathrm{B}}$ & $483.02 \pm 8.38^{\mathrm{A}}$ & $25.61 \pm 0.89^{\mathrm{B}}$ \\
$0.1 \mathrm{~F}: \mathrm{L}$ & $18.12 \pm 0.76^{\mathrm{B}}$ & $458.33 \pm 11.15^{\mathrm{A}}$ & $25.46 \pm 0.96^{\mathrm{B}}$ \\
Effect of treatment & & & \\
$P$ & 0.001 & 0.282 & 0.001 \\
\hline
\end{tabular}


Table 2. Photosynthetic pigments of 'Brigitta' blueberry leaves from girdled branches with 10 (10F:L), 1 (1F:L), and 0.1 (0.1F:L) fruits per leaf and nongirdled branches bearing one fruit per leaf (NG). Means of treatments $(n=18)$, standard errors, effect of treatment and letters indicating significantly different values at $P<0.05$ (Tukey's test) are presented. Car - carotenoids; Chl tot - total chlorophylls; Chl $a / b$ - chlorophyll $a / b$ ratio; FM - fresh mass.

\begin{tabular}{lllll}
\hline Treatment & $\mathrm{Chl}_{\text {tot }}\left[\mathrm{mg} \mathrm{g}^{-1}(\mathrm{FM})\right]$ & $\mathrm{Chl} a / b$ & $\mathrm{Car}\left[\mathrm{mg} \mathrm{g}^{-1}(\mathrm{FM})\right]$ & $\mathrm{Car} / \mathrm{Chl}_{\text {tot }}$ \\
\hline $\mathrm{NG}$ & $1.18 \pm 0.06^{\mathrm{A}}$ & $1.44 \pm 0.05^{\mathrm{AB}}$ & $0.11 \pm 0.007^{\mathrm{A}}$ & $0.09 \pm 0.005^{\mathrm{AB}}$ \\
$10 \mathrm{~F}: \mathrm{L}$ & $1.19 \pm 0.04^{\mathrm{A}}$ & $1.28 \pm 0.07^{\mathrm{A}}$ & $0.09 \pm 0.014^{\mathrm{A}}$ & $0.07 \pm 0.011^{\mathrm{A}}$ \\
$1 \mathrm{~F}: \mathrm{L}$ & $1.07 \pm 0.03^{\mathrm{AB}}$ & $1.57 \pm 0.06^{\mathrm{B}}$ & $0.13 \pm 0.011^{\mathrm{A}}$ & $0.12 \pm 0.008^{\mathrm{BC}}$ \\
$0.1 \mathrm{~F}: \mathrm{L}$ & $0.96 \pm 0.07^{\mathrm{B}}$ & $1.50 \pm 0.06^{\mathrm{AB}}$ & $0.13 \pm 0.009^{\mathrm{A}}$ & $0.13 \pm 0.008^{\mathrm{C}}$ \\
Effect of treatment & & & & \\
$P$ & 0.020 & 0.021 & 0.069 & 0.003 \\
\hline
\end{tabular}

Table 3. Matrix of correlation coefficients among the evaluated variables for the main effect of treatment. C - carbon; Chl tot - total chlorophyll; Chl $a / b$ - chlorophyll $a / b$ ratio; Car - carotenoids; DM - dry mass; FM - fresh mass; $g_{\mathrm{s}}$ - stomatal conductance; $\mathrm{N}$ - nitrogen; $P_{\max }$ - light-saturated photosynthesis; $R_{\mathrm{D}}$ - dark respiration rate; SSC - soluble sugar concentration; WUE - intrinsic water-use efficiency. Levels of statistical significance are: ${ }^{*} P<0.05,{ }^{* *} P<0.01$, and ${ }^{* * *} P<0.001$.

\begin{tabular}{|c|c|c|c|c|c|c|c|c|c|}
\hline & $g_{\mathrm{s}}$ & WUE $_{i}$ & $R_{\mathrm{D}}$ & $\mathrm{SSC}$ & $\mathrm{C} / \mathrm{N}$ & $\mathrm{N}$ & Chl tot $_{\text {t }}$ & $\mathrm{Chl} a / b$ & Car/Chl tot \\
\hline$P_{\max }$ & $0.93^{* * *}$ & $-0.7^{* *}$ & $-0.64^{*}$ & $-0.94^{* * *}$ & $-0.76^{* *}$ & $0.72^{* *}$ & 0.52 & -0.39 & $-0.63^{*}$ \\
\hline$g_{\mathrm{s}}$ & & $-0.84^{* * *}$ & -0.58 & $-0.86^{* * *}$ & $-0.75^{* *}$ & $0.71^{\text {** }}$ & 0.57 & -0.40 & -0.62 \\
\hline WUE $_{i}$ & & & 0.53 & $0.66^{*}$ & 0.56 & -0.59 & $-0.73^{* *}$ & 0.31 & 0.58 \\
\hline$R_{\mathrm{D}}$ & & & & 0.56 & $0.67^{*}$ & $-0.72^{* *}$ & -0.60 & 0.16 & 0.44 \\
\hline SSC & & & & & $0.67^{*}$ & $-0.65^{*}$ & -0.52 & 0.34 & $0.63^{*}$ \\
\hline $\mathrm{C} / \mathrm{N}$ & & & & & & & -0.50 & 0.26 & 0.40 \\
\hline $\mathrm{N}$ & & & & & & & 0.55 & -0.19 & -0.42 \\
\hline Chl tot & & & & & & & & -0.21 & -0.60 \\
\hline Chl $a / b$ & & & & & & & & & $0.80^{* * *}$ \\
\hline
\end{tabular}

Correlation among variables as affected by treatments:

As $\mathrm{C}$ and Car were unaffected by treatments, these variables were excluded from the correlation analysis. The $P_{\max }$ was positively and highly correlated to $g_{\mathrm{s}}$ and $\mathrm{N}$ and negatively correlated to most of the other variables except for $\mathrm{Chl}_{\text {tot }}$ and $\mathrm{Chl} a / b$ for which no significant correlation was observed (Table 3). The $g_{\mathrm{s}}$ showed similar negative

\section{Discussion}

Effect of treatments on the studied variables: Our results showed that ten days after applying the source-sink treatments, adjustments in the measured variables had already occurred in response to the new levels of carbon demand imposed by the treatments. The reduction in carbon demand brought about by girdling and reduced fruit load induced a negative effect on $P_{\max }$ values (Fig. 1A), which were in the range of those reported by Maust et al. (1999) for the 'Sharpblue' southern blueberry cultivar under different fruit densities (number of fruits per $\mathrm{cm}$ of fruit-bearing shoot). For the NG and 10F:L treatments, $P_{\max }$ rates were apparently not or slightly limited by sink feedback, exhibiting similar $P_{\max }$ values to those estimated from light-response curves performed on plants with higher fruit load than the one of the $\mathrm{NG}$ treatment (daily mean equal to $11.56 \pm 0.4 \mu \operatorname{mol}\left(\mathrm{CO}_{2}\right) \mathrm{m}^{-2} \mathrm{~s}^{-1}, n=21$, unpublished data). The similarity of $P_{\max }$ for the $\mathrm{NG}$ and and positive significant correlations for the same variables as $P_{\max }$, except $R_{\mathrm{D}}$. The WUE $\mathrm{W}_{\mathrm{i}}$ correlated positively to SSC and negatively to $\mathrm{Chl}_{\text {tot. }}$. The $R_{\mathrm{D}}$ was negatively correlated to $\mathrm{N}$ and positively correlated to SSC. The $\mathrm{C} / \mathrm{N}, \mathrm{N}$, and $\mathrm{Chl}_{\text {tot }}$ did not present significant correlations. The $\mathrm{Chl} a / b$ ratio was positively correlated to the $\mathrm{Car} / \mathrm{Chl}_{\text {tot }}$ ratio.

10F:L treatments indicated that organs other than fruits have enough carbon demand to sustain high assimilation rates in the NG treatment and that fruit-bearing shoots exported $\mathrm{C}$ assimilates to the rest of the plant (Fig. 1A). This is consistent with the fact that carbon partitioning towards vegetative growth is increased by reducing fruit load in several species, including blueberry (Maust et al. 1999). Alternatively, the ability of the fruit, both as carbon consumer and driving force for higher assimilation rates, can be observed in the significant increase of $P_{\max }$ in the 10F:L treatment, where the depressing effect of girdling on $P_{\max }$ was appeased (Fig. $1 A$ ).

$P_{\max }$ and $g_{\mathrm{s}}$ were strongly correlated (Fig. 2, Table 4), which suggests that the co-regulation of photosynthesis and transpiration was not affected by the treatments, in agreement with results found in $M$. indica (Urban et al. 2004) and in Coffea arabica L. (Franck et al. 2006). On 
the other hand, lower $g_{\mathrm{s}}$ was not associated with lower intercellular $\mathrm{CO}_{2}$ concentration $\left(C_{\mathrm{i}}\right)$, demonstrating that the depressing effect on $P_{\max }$ was not attributable to a $g_{\mathrm{s}^{-}}$ associated decrease in $C_{\mathrm{i}}$ (data not shown).

The direct dependency of $P_{\max }$ on $g_{\mathrm{s}}$ (Fig. 2) resulted in higher $\mathrm{WUE}_{\mathrm{i}}$ when a reduced photosynthetic rate occurred. Similar results were found by Gilbert et al. (2011), in different Glycine $\max (\mathrm{L}$.) Merr genotypes subjected to mild drought. Our results imply that the amount of carbon gained per unit of water used was enhanced when 'Brigitta' blueberry leaves were experiencing lower reproductive sink demand.

A strong negative correlation between $P_{\max }$ and SSC was observed for the whole data set (Fig. 3), which increased when the data were arranged as daily means of the treatments (Table 3). This confirmed the hypothesis that nonstructural carbohydrates are involved in sink feedback downregulation of photosynthesis in blueberry leaves, as reported for other woody crops (e.g., Wünsche et al. 2005, Franck et al. 2006,). Sugar biosynthesis in leaves is likely to have exceeded the rate of export to sinks, leading to accumulation of sugars, which decreased the expression of photosynthetic gene promoters (Koch et al. 1992, Jang and Sheen 1994, Eberhard et al. 2008).

Daily mean $R_{\mathrm{D}}$ increased when fruit load was reduced (Fig. 1D). Avery et al. (1979), reported that $R_{\mathrm{D}}$ increased by $32 \%$ when sinks were restricted in $M$. domestica trees; but Urban et al. (2004) did not find any significant effect of sink on $R_{\mathrm{D}}$ in $M$. indica leaves. Higher respiration rates have been closely related to both higher substrate availability in leaves and higher photosynthetic rate (Noguchi 2005). Our results showed that $R_{\mathrm{D}}$ and SSC were not significantly correlated (Table 3 ), which indicates that respiration was independent of substrate availability. In addition, the negative significant correlation found between $P_{\max }$ and $R_{\mathrm{D}}$ suggests that higher respiratory rates in leaves of blueberry cv. 'Brigitta' were not directly related to carbon gain under our study conditions (Table 3). Similar observations have been previously reported in Alocasia macrorrhiza L. (Noguchi et al. 1997) and Pisum sativum L. (Azcon-Bieto et al. 1983). According to Noguchi (2005), high rates of processes that use respiratory products (nutrient export and protein turnover) are involved in higher respiration rates uncoupled with leaf carbohydrate status. Considering that $R_{\mathrm{D}}$ was negatively correlated to N (Table 3 ), it is probable that a high respiration rate was due to an increased nitrogen remobilization for developing new sink capacity (Paul and Foyer 2001).

Under the presently evaluated conditions, $\mathrm{N}$ was positively correlated to $P_{\max }$ (Table 3 ), which confirmed that carbon and nitrogen balance are highly related and coregulated in function of sink demand (Thiebus-Kaesberg and Lenz 1994, Paul and Driscoll 1997). In fact, the strong negative correlation of $P_{\max }$ to $\mathrm{C} / \mathrm{N}$ summarizes this assumption, despite that changes in $\mathrm{C} / \mathrm{N}$ ratio were driven only by variation in $\mathrm{N}$ (Table 1 ).
The $\mathrm{Chl}_{\text {tot }}$ stabilized at low values with the decreasing sink demand (Table 2). As previously reported by Wünsche et al. (2005) and Nii (1997), a decrease in the Chl concentration of leaves was stimulated by removal of fruits in M. domestica and in Prunus persica (L.) Batch trees, respectively. Although $\mathrm{Ch}_{\text {tot }}$ was not significantly correlated to $P_{\max }(P=0.19$; Table 3$)$, a low Chl concentration reduces the absorption of excess radiant energy by leaves (Niinemets 2007), diminishing the risk of photoinhibition under conditions in which carbon use is low. In this way, the increase of both $\mathrm{Car} / \mathrm{Chl}_{\text {tot }}$ and $\mathrm{Chl} a / b$ ratio was associated with the decreasing sink demand (Table 2), in addition to the high correlation between these variables (Table 3), which indicates that a low sink demand induced adjustments of the light-harvesting pools with a trend for reducing antenna size accompanied to increasing the Car pool per unit of Chl. This probably was done in order to enhance photoprotection, as it occurs in leaves acclimated to high irradiances (Hallik et al. 2012). Higher protection from excessive radiant energy is also associated with increasing the relative concentration of Car with respect to $\mathrm{Chl}_{\text {tot }}$ (Demmig-Adams 1990, Gonçalves et al. 2005). As observed in Table 2, the $\mathrm{Car} / \mathrm{Chl}_{\text {tot }}$ ratio was significantly affected by the treatments with leaves exhibiting higher ratios when the sink demand was reduced. The interpretation of increased $\mathrm{Car} / \mathrm{Chl}_{\text {tot }}$ as a photoprotective mechanism under conditions of downregulated photosynthesis can also explain the negative correlation found between $P_{\max }$ and Car/Chl tot (Table 3). On the other hand, the significant and positive correlation between $\mathrm{Car} / \mathrm{Chl}_{\text {tot }}$ and SSC (Table 3), confirmed the association existing between levels of photoprotection and accumulation of sugars in leaves, as an adaptive response to a stressfull condition (Roitsch 1999). As photoprotection has a high energy cost (Raven 2011), the activation of such mechanisms could also explain the higher $R_{\mathrm{D}}$ observed in low sink-demand treatments (Fig. 1C).

Diurnal dynamics of gas-exchange parameters and SSC: Leaf metabolism is generally regulated in order to maintain a relatively steady carbon supply to meet demand of growing sinks throughout day/night periods (Fondy and Geiger 1982, Geiger and Servaites 1994). Regardless of the treatment, our data suggest that a gradual reduction in carbon use by fruits over the course of the day occurred (tentatively the daily rate of carbon demand in sinks slowed in response to a circadian rhythm), leading to a gradual accumulation of sugars in leaves in concomitance with a decreasing photosynthetic capacity. In fact, our results showed a high correlation between $P_{\max }$ and SSC when taking the data of all the periods of the day ( $r=$ $-0.88, P<0.001, n=72$ ), which confirmed the major effect of sugar concentration on photosynthetic performance over the diurnal cycle (Eberhard et al. 2008). The gradual accumulation of sugars in leaves allows time for the acclimation and restoration of the balance in leaf metabolism (Geiger and Servaites 1994) and for generating 
substrates to support the night-time growth and maintenance processes in the absence of photosynthesis (Walter and Schurr 2005, Nozue and Maloof 2006). Our results showed that sugars accumulated in leaves were consumed during the night (Fig. $1 E$ ), resulting in the highest $P_{\max }$ rates at $\mathrm{AM}$, regardless of the treatment (Fig. 1A). Nonetheless, as less substrate was consumed in sinklimited treatments during the night period, more carbohydrate for translocation to the developing sinks was available on the subsequent day, which resulted in a downregulated $P_{\max }$ for the $1 \mathrm{~F}: \mathrm{L}$ and $0.1 \mathrm{~F}: \mathrm{L}$ treatments in the morning.

The $P_{\max }$ of the NG, $10 \mathrm{~F}: \mathrm{L}$, and $1 \mathrm{~F}: \mathrm{L}$ treatments remained unchanged from $\mathrm{AM}$ to noon (Fig. 1A), indicating that levels of carbon consumption by sinks were enough to avoid an early accumulation of sugars (Fig. $1 E$ ) and reduction of photosynthetic rate. The $P_{\max }$ of the $0.1 \mathrm{~F}: \mathrm{L}$ treatment was significantly reduced and stabilized at a low value at noon, contrasting with observations in the other treatments (Fig. 1A). This lower $P_{\max }$ was not accompanied with a significant increase in SSC (Fig. 1E), which suggests that mechanisms other than sugar-sensing may play an important role on $P_{\max }$ of 'Brigitta' blueberry leaves under severely reduced carbon demand. In this sense, an increased content of reactive oxygen species produced by excess absorbed light when low sink demand represses photosynthesis, might result in a photodamage that overcame repair rates of PSII, resulting in a photoinhibition of PSII. Although we did not measure Chl $a$ fluorescence parameters, leaves from $P$. persica shoots with reduced fruit load exhibited photooxidative damage when higher irradiances were recorded under field conditions (Duan et al. 2008).

Changes in $P_{\max }$ and $g_{\mathrm{s}}$ were sufficiently coordinated as to maintain $\mathrm{WUE}_{\mathrm{i}}$ values from AM to noon, irrespective of the treatment. This coordinated response was altered in the afternoon with $g_{\mathrm{s}}$ decreasing more than $P_{\max }$, which tended to increase $\mathrm{WUE}_{\mathrm{i}}$ for the $\mathrm{NG}, 10 \mathrm{~F}: \mathrm{L}$, and $1 \mathrm{~F}: \mathrm{L}$ treatments. Although, vapour pressure deficit was not a factor in this

\section{References}

Avery D.J., Priestley C.A., Treharne K.J.: Integration of assimilation and carbohydrate utilization of apple - In: Marcelle R., Clijsters H., van Pouke W. (ed.): Photosynthesis and Plant Development. Pp. 221-231. Dr. W. Junk Publishers, The Hague 1979.

Azcon-Bieto J., Lambers H., Day D.A.: Respiratory properties of developing bean and pea leaves. - Aust. J. Plant Physiol. 10: 237-245, 1983.

Bartoli C.G., Gomez F., Gergoff G. et al.: Up-regulation of the mitochondrial alternative oxidase pathway enhances photosynthetic electron transport under drought conditions. - J. Exp. Bot. 56: 1269-1276, 2005.

Demmig-Adams B.: Carotenoids and photoprotection in plants. A role for the xanthophyll zeaxanthin. - BBA-Bioenergetics 1020: 1-24, 1990.

Duan W., Fan P.G., Wang L.J. et al.: Photosynthetic response to low sink demand after fruit removal in relation to study, an increased stomatal closure in response to a high leaf-to-air vapour pressure difference in the afternoon might explain reductions in $g_{\mathrm{s}}$ (Yong et al. 1997).

The $R_{\mathrm{D}}$ was higher at noon in the $1 \mathrm{~F}: \mathrm{L}$ treatment, when leaves were subjected to the highest irradiances and temperature. At that time of the day, an enhanced upregulation of alternative oxidase pathway possibly occurred in the $1 \mathrm{~F}: \mathrm{L}$ treatment, which could contribute to increase the carbohydrate consumption and to the size of sink for reducing power (Bartoli et al. 2005), diminishing, in turn, the loss of photosynthesis and the deleterious effect of light absorption under conditions in which no high photosynthesis rates are demanded.

Conclusion: The reduction in carbon demand brought about by girdling and reduced fruit load induced a negative effect on $P_{\max }$, which was mediated and modulated, in the course of the day, by accumulation of sugars (SSC) in leaves. $P_{\max }$ and $g_{\mathrm{s}}$ changed in parallel, furthermore the relationship found between these variables increased $W E_{i}$ both under reduced sink demand conditions and through the course of the day. When low photosynthetic rates were demanded, $\mathrm{N}$ and $\mathrm{Chl}_{\text {tot }}$ were reduced, while the $\mathrm{Car} / \mathrm{Chl}_{\text {tot }}$ ratio increased. These findings suggest that structural photosynthetic proteins were reallocated and, concomitantly, a reduced absorption of excess radiation and higher levels of photoprotection occurred. The $R_{\mathrm{D}}$ negatively correlated to $P_{\max }$ and did not correlate to SSC, which reveals that higher respiratory rates under low sink demand were not positively related to carbon gain and availability. On the other hand, increasing respiration rates might contribute to $\mathrm{N}$ export, as $R_{\mathrm{D}}$ significantly correlated to $\mathrm{N}$ or to photoprotection. Our results showed that manipulating the source-sink relationships in blueberry cv. 'Brigitta' led to a rearrangement of physiological and structural leaf traits, which allowed adjusting the daily balance between carbon assimilation and absorbed light energy.

photoinhibition and photoprotection in peach trees. - Tree Physiol. 28: 123-132, 2008.

Eberhard S., Finazzi G., Wollman F.A.: The dynamics of photosynthesis. - Annu. Rev. Genet. 42: 463-515, 2008.

Famiani F., Antognozzi E., Boco M. et al.: Effects of altered source-sink relationships on fruit development and quality in Actinidia deliciosa. - Acta Hortic. 444: 355-360, 1997.

Fondy B.F., Geiger D.R.: Diurnal pattern of translocation and carbohydrate metabolism in source leaves of Beta vulgaris L. - Plant Physiol. 70: 671-676, 1982.

Franck N., Vaast P., Génard M. et al.: Soluble sugars mediate sink feedback down-regulation of leaf photosynthesis in fieldgrown Coffea arabica. - Tree Physiol. 26: 517-525, 2006.

Geiger D.R., Servaites J.C.: Diurnal regulation of photosynthetic carbon assimilation. - Annu. Rev. Plant Physiol. 45: 235-256, 1994.

Gilbert M.E., Zwieniecki M.A., Holbrook N.M.: Independent 
variation in photosynthetic capacity and stomatal conductance leads to differences in intrinsic water use efficiency in 11 soybean genotypes before and during mild drought. - J. Exp. Bot. 62: 2875-2887, 2011.

Gonçalves J.F.C., Barreto D.C.S., Santos Junior U.M. et al.: Growth, photosynthesis and stress indicators in young rosewood plants (Aniba rosaeodora Ducke) under different light intensities. - Braz. J. Plant Physiol. 17: 325-334, 2005.

Hallik L., Niinemets Ü., Kull O.: Photosynthetic acclimation to light in woody and herbaceous species: a comparison of leaf structure, pigment content and chlorophyll fluorescence characteristics measured in the field. - Plant Biol. 14: 88-99, 2012.

Hendrix D.L., Huber S.C.: Diurnal fluctuations in cotton leaf carbon export, carbohydrate content and sucrose synthesizing enzymes. - Plant Physiol. 81: 584-586, 1986.

Iglesias D.J., Lliso I., Tadeo F.R. et al.: Regulation of photosynthesis through source: sink imbalance in citrus is mediated by carbohydrate content in leaves. - Physiol. Plantarum 116: 563-572, 2002.

Jang J.C., Sheen J.: Sugar sensing in higher plants. - Plant Cell 6: 1665-1679, 1994.

Jorquera-Fontena E., Alberi M., Franck N.: Pruning severity affects yield, fruit load and fruit and leaf traits of 'Brigitta' blueberry. - J. Soil Sci. Plant Nutr. 14: 855-868, 2014.

Koch K.E., Nolte K.D., Duke E.R. et al.: Sugar levels modulate differential expression of maize sucrose synthase genes. - Plant Cell 4: 59-69, 1992.

Layne D.R., Flore J.A.: End-product inhibition of photosynthesis in Prunus cerasus L. in response to whole-plant source-sink manipulation. - J. Am. Soc. Hortic. Sci. 120: 583-599, 1995.

Lichtenthaler H.K., Wellburn A.R.: Determinations of total carotenoids and chlorophylls $a$ and $b$ of leaf extracts in different solvents. - Biochem. Soc. T. 11: 591-592, 1983.

Ludewig F., Sonnewald U.: High $\mathrm{CO}_{2}$-mediated down-regulation of photosynthetic gene transcripts is caused by accelerated leaf senescence rather than sugar accumulation. - FEBS Lett. 479: 19-24, 2000.

Maust B.E., Williamson J.G., Darnell R.L.: Effects of flower bud density on vegetative and reproductive development and carbohydrate relations in southern highbush blueberry. - J. Am. Soc. Hortic. Sci. 124: 532-538, 1999.

Nebauer S.G., Renau-Morata B., Guardiola J.L.: Photosynthesis down-regulation precedes carbohydrate accumulation under sink limitation in Citrus. - Tree Physiol. 31: 169-177, 2011.

Nii N.: Changes of starch and sorbitol in leaves before and after removal of fruits from peach trees. - Ann. Bot.-London 79: 139-144, 1997.
Niinemets Ü.: Photosynthesis and resource distribution through plant canopies. - Plant Cell Environ. 30: 1052-1071, 2007.

Noguchi K., Terashima I.: Different regulation of leaf respiration between Spinacia oleracea, a sun species, and Alocasia odora, a shade species. - Physiol. Plantarum 101: 1-7, 1997.

Noguchi K.: Effects of light intensity and carbohydrate status on leaf and root respiration - In: Labert H., Ribas-Carbo M. (ed.): Plant Respiration. Pp. 63-83. Springer, Dordrecht 2005.

Nozue K., Maloof J.N.: Diurnal regulation of plant growth. Plant Cell Environ. 29: 396-408, 2006.

Paul M.J., Driscoll S.P.: Sugar repression of photosynthesis: the role of carbohydrates in signalling nitrogen deficiency through source:sink imbalance. - Plant Cell Environ. 20: 110-116, 1997.

Paul M.J., Foyer C.H.: Sink regulation of photosynthesis. - J. Exp. Bot. 52: 1383-1400, 2001.

Proeitti P.: Effect of fruiting on leaf gas exchange in olive (Olea europaea L.). - Photosynthetica 38: 397-402, 2000.

Raven J.A.: The cost of photoinhibition. - Physiol. Plantarum 142: 87-104, 2011.

Roe J.H.: A colorimetric method for the determination of fructose in blood and urine. - J. Biol. Chem. 107: 15-22, 1934.

Roitsch T.: Source-sink regulation by sugar and stress. - Curr. Opin. Plant Biol. 2: 198-206, 1999.

Strik B., Buller G., Hellman E.: Pruning severity affects yield, berry weight, and hand harvest efficiency of highbush blueberry. - HortScience 38: 196-199, 2003.

Swain P.A., Darnell R.L.: Production systems influence source limitations to growth in 'Sharpblue' southern highbush blueberry. - J. Am. Soc. Hortic. Sci. 127: 409-414, 2002.

Thiebus-Kaesberg P., Lenz F.: Effect of fruit load on growth, carbohydrate and mineral concentrations of leaves of 'Golden Delicious' apple trees. - Erwerbsobstbau 36: 130-133, 1994.

Urban L., Léchaudel M., Lu P.: Effect of fruit load and girdling on leaf photosynthesis in Mangifera indica L. - J. Exp. Bot. 44: 2075-2085, 2004.

Walter A., Schurr U.: Dynamics of leaf and root growth: endogenous control versus environmental impact. - Ann. Bot.London 95: 891-900, 2005.

Wingler A., Marès M., Pourtau N.: Spatial patterns and metabolic regulation of photosynthetic parameters during leaf senescence. - New Phytol. 161: 781-789, 2004.

Wünsche J.N., Greer D.H., Laing W.A. et al.: Physiological and biochemical leaf and tree responses to crop load in apple. Tree Physiol. 25: 1253-1263, 2005.

Yong J.W.H., Wong S.C., Farquhar G.D.: Stomatal responses to changes in vapour pressure difference between leaf and air. Plant Cell Environ. 20: 1213-1216, 1997. 